\title{
Study on the Effects of Hierarchical Wavy Morphology on Clearance Flow
}

\author{
Xi Zhang 1,* - Tianlu Zhang1 - Xiangyu Geng ${ }^{1}$ - Jianfeng Hong 1 - Jinjun $\mathrm{Wu}^{2}$ \\ ${ }^{1}$ China University of Mining \& Technology, Beijing, School of Mechanical Electronic \& Information Engineering, China \\ ${ }^{2}$ China Academy of Machinery Science \& Technology, China
}

This paper aims to explore the influences of multilevel sinusoidal structures on clearance flow by using numerical and experimental methods. A hierarchical sinusoidal morphology was proposed to design the gap between matching surfaces in water hydraulic systems. The specimens with the $0^{\text {th }}$ order, the $1^{\text {st }}$ order and the $2^{\text {nd }}$ order sinusoidal structures were machined by a three dimensional (3D) printer, and their clearance leakage flow was tested on a water hydraulic annular clearance test rig. An extensive simulation study on the effects of waved surfaces with varying amplitudes and wavelengths on leakage was presented. Both the experimental and numerical results show that introducing hierarchical morphology on clearance surfaces will reduce leakage. Moreover, it was found that the leakage decreases with the increase of the ratio of the amplitude to wavelength. Further study of the flow field reveals that the leakage reduction of the $2^{\text {nd }}$ order sinusoidal model is obtained due to the extra vortexes of various scales and the narrower width of the main flow and lower velocity. Moreover, our results indicate that the waved surface induces a micro-hydrodynamic effect that creates an additional load carrying capability, which is helpful for separating the matching surfaces to reduce wear. The study is beneficial to investigate the potential for improving efficiency through the optimization of gap design.

Keywords: hierarchical sinusoidal morphology, clearance flow, water, leakage

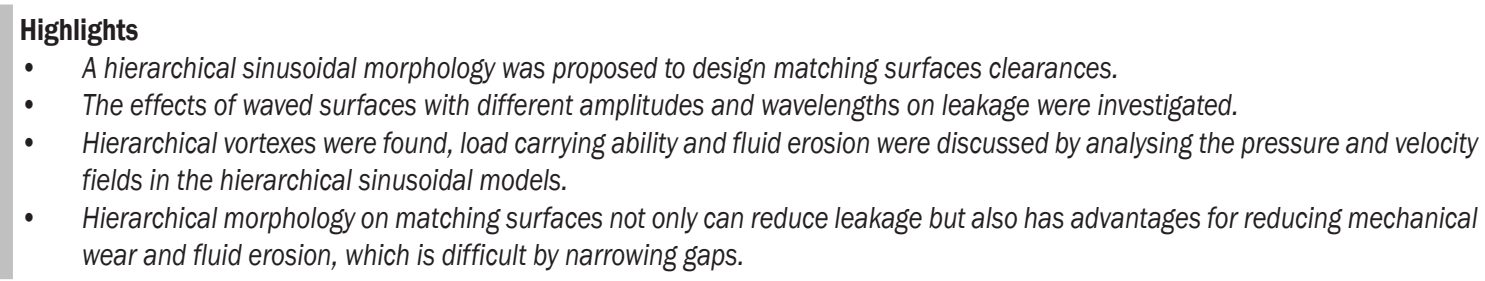

\section{INTRODUCTION}

Clearances broadly exist in hydraulic components, such as the matching clearances of piston/cylinder, swash plate/slipper pad and cylinder block/valve plate, etc., in which most of the energy is dissipated by friction and leakage [1]. With the increasing demand for an environmentally friendly, non-flammable, readily available and hygienic fluid medium in hydraulic systems, water used as a pressure medium has caused renewed interest. However, the kinematic viscosities of water and mineral oil are $1 \mathrm{~m}^{2} / \mathrm{s}$ and 29 $\mathrm{m}^{2} / \mathrm{s}$ at room temperature at atmospheric pressure, respectively. Lower viscosity is accompanied by poorer lubricity and larger leakage. For certain matching clearances, the leakage rate of water is larger than that of oil, which will cause more internal and external leakages for water hydraulic systems [2]. Therefore, smaller clearances have to be considered in order to achieve reduced leakage. However, narrower gaps in water hydraulic components will cause mechanical wear [1] and [3] and fluid erosion [4] due to the poor lubrication of water, which will enlarge gaps, leading to more leakage [5].

Surface topography technology has emerged in recent years as an effective method to reduce energy dissipation [6] to [8]. Recent works on various forms and shapes of surface texturing for high efficiency [9] and [10], energy-saving [11] and [12] and long performance life [13] and [14] have been carried out, which has already succeeded in many industrial applications [8], [15] and [16], such as seals [17] and [18], bearings [19] and [20] and gears [21] and [22]. An attempt to optimize piston topography to minimize energy dissipation within the piston cylinder interface was made by Wondergem and Ivantysynova [23] and Ivantysynova [24], who proposed a barrel-like piston. Ivantysynova and Lasaar [25] demonstrated the potential of an advanced gap design using computer simulation. The load carrying ability, piston friction force and gap flow were computed for all investigated surface variations, and then an improved barrel-like piston was proposed to reduce energy dissipation generated by piston/cylinder assembly. Kleist [26] also studied pistons with different shapes for radial piston 
machines. The results showed that the piston with surface morphology has lower friction and leakage comparable to the traditional one. Ivantysynova and Baker [27] applied a sinusoidal micro-structured waved surface to the valve plate gap surface for reducing power loss, and their results show that the waved surface significantly reduce power losses at lower operating pressures; however, the leakage of waved surface designs are higher than that of the standard designs, which is caused by larger gap heights. Pelosi and Ivantysynova [28] numerically studied the cylinder block with a brass bushing. Their results showed that the wavy surface, caused by the thermal deformation of the brass bushing, has an impact on the energy dissipation generated by viscous friction and leakage flow. Shin and Kim [29] studied the influence of various peak-to-valley amplitudes and wavelengths of surface waviness on leakage power loss and friction power loss. Their results revealed that proper surface design can improve reliability and power efficiency. Shen and Khonsari [10] investigated the tribological and sealing performance of a piston ring with a specially designed textured surface in a diesel engine. They found that lasered pockets led to a reduction of up to about $15 \%$ in the total friction between cylinder liner and piston assembly and also improved the sealing performance compared to untextured piston rings. For piston ring-liners (PRL), recent developments in ring surface modification through laser surface texturing have shown promising results in improving tribological characteristics. Usman and Park [12] considered asymmetric PRL contact of a textured piston ring in a distorted bore, and found that optimized surface textures improve the tribological performance of a PRL interface, whereas textures with large lateral aspect ratios have a detrimental effect. Rao et al. [16] studied the performance of the cylinder liner-piston ring with different surface textures (1 $\mathrm{mm}, 2 \mathrm{~mm}, 3 \mathrm{~mm}$, and $4 \mathrm{~mm}$ widths) in marine diesel settings; the results showed that the $2 \mathrm{~mm}$ groove structure of the cylinder liner is more favourable for improving the wear performances at low speed, whereas a $3 \mathrm{~mm}$ groove structure of the cylinder liner is more suitable for improving the wear performance at higher speeds. Taken together, plentiful efforts have been carried out to improve the tribological properties and sealing performance via the rational design of surface morphology. However, little attention is paid to the effects of hierarchical morphology on the gap flow. Interestingly, many biological materials are hierarchically structured with wavy morphology, for example, towel gourd tendrils [30] and bovine horns [31].
Inspired by the unique hierarchical structures in nature, this paper proposed a hierarchical sinusoidal morphology for designing clearances between matching surfaces in water hydraulic systems in which poorer lubricity and larger leakage occur due to the lower viscosity of water. We tested the leakage flow of the models with $0^{\text {th }}$ order, $1^{\text {st }}$ order, and $2^{\text {nd }}$ order sinusoidal structures on the water hydraulic annular clearance test rig. Further studies on the effects of waved surfaces with various amplitudes and wavelengths on leakage were carried out using numerical simulation. The velocity and pressure fields generated in the clearances were analysed to give further explanations of experimental observation. Both the experimental and simulated results suggest that hierarchical sinusoidal structures in the clearances between matching surfaces are beneficial to leakage reduction.

\section{EXPERIMENTAL}

\subsection{Generation of the $2^{\text {nd }}$ Order Sinusoidal Hierarchical Wave}

The $2^{\text {nd }}$ order sinusoidal curves were obtained based on the following equations[31]. As shown in Fig. 1, the sine arc length from the origin point $O$ to an arbitrary point $N\left(p_{1}, q_{1}\right)$ can be described as follows:

$$
\begin{aligned}
s & =\int_{0}^{p} \sqrt{1+\left(d q_{1} / d p_{1}\right)^{2}} d p_{1} \\
& =\int_{0}^{p} \sqrt{1+\left[\frac{2 \pi A_{1}}{\lambda_{1}} \cos \left(\frac{2 \pi}{\lambda_{1}} p_{1}\right)\right]^{2}} d p_{1},
\end{aligned}
$$

where $A_{1}$ and $\lambda_{1}$ are the amplitude and wavelength of the $1^{\text {st }}$ order sinusoidal curve $C_{1}, p_{1}$ and $q_{1}$ are horizontal and vertical coordinates, respectively. The sinusoidal $2^{\text {nd }}$ order hierarchical wave $C_{2}$ is superimposed on the $1^{\text {st }}$ order wave, and its amplitude $A_{2}$ and wavelength $\lambda_{2}$ can be calculated on the curvilinear coordinate system along $C_{1}$ :

$$
q_{2}=A_{2} \sin \left(\frac{2 \pi}{\lambda_{2}} s\right)
$$

Likewise, the $2^{\text {nd }}$ order sinusoidal curve can be described by the equation in the $X O Y$ coordinate system with $p$ as its free parameter:

where $\alpha$ is given by 


$$
\alpha=\tan ^{-1}\left[\frac{2 \pi A_{1}}{\lambda_{1}} \cos \left(\frac{2 \pi}{\lambda_{1}} p_{1}\right)\right] .
$$

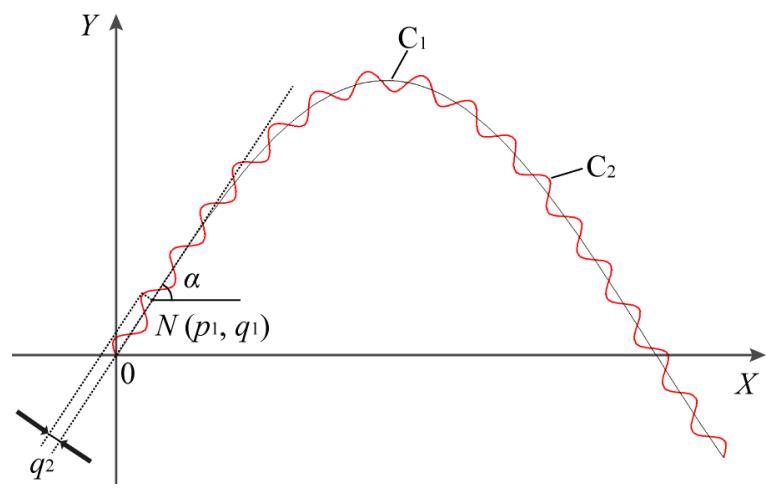

Fig. 1. Illustration of the method for generating the $2^{\text {nd }}$ order hierarchical wave

\subsection{Test Specimens}

Three kinds of models were designed: $0^{\text {th }}$ order model, $1^{\text {st }}$ order sinusoidal model, and $2^{\text {nd }}$ order sinusoidal model, as shown in Fig. 2. The clearance, $\delta$, equals $0.2 \mathrm{~mm}$. Compared to the $0^{\text {th }}$ order model, the $1^{\text {st }}$ order model is characterized by sinusoidal waviness with amplitude $A_{1}$ and wavelength $\lambda_{1}$. The $2^{\text {nd }}$ order model has two-level hierarchical sinusoidal structures; apparently, it was superimposed on the $1^{\text {st }}$ order sinusoidal structure with the amplitude $A_{2}<A_{1}$ and wavelength $\lambda_{2}<\lambda_{1}$.

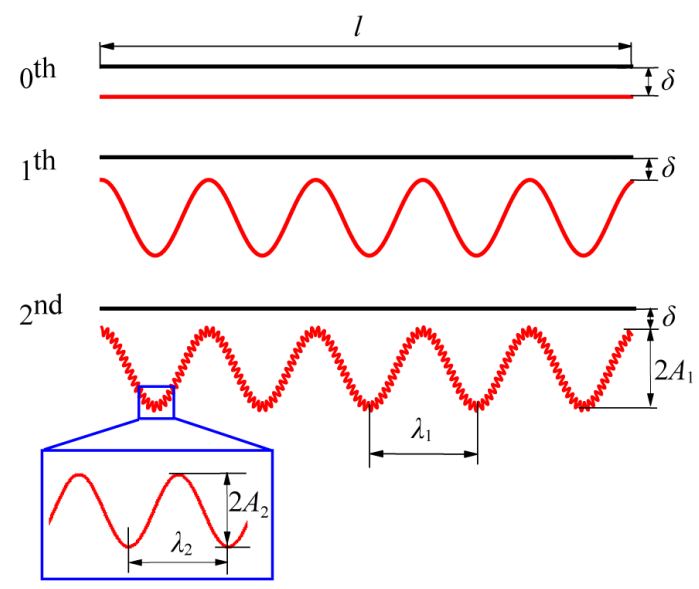

Fig. 2. The clearance models with the $0^{\text {th }}$ order, the 1st order, and the $2^{\text {nd }}$ order sinusoidal morphology

Three dimensional (3D) printing technology was considered to manufacture these models, and
Lite $6003 \mathrm{D}$ printer with $0.05 \mathrm{~mm}$ print precision was employed. The material used is Acrylonitrile Butadiene Styrene (ABS). The parameters of the 3D printed specimens are shown in Table 1 , while 3D printed specimens are shown in Fig. 3. The whole length of the specimen is $131 \mathrm{~mm}$, including both the work length $111 \mathrm{~mm}$ and the interference fit length 10 $\mathrm{mm}$ on its either ends. Enlarged views of the specimen are shown in Fig. 4.

Table 1. The design and printed parameters of specimens

\begin{tabular}{|c|c|c|c|}
\hline Specimen & $0^{\text {th }}$ order & $1^{\text {st }}$ order & $2^{\text {nd }}$ order \\
\hline $\begin{array}{l}\text { Designed } \\
\text { amplitude and } \\
\text { wavelength } \\
{[\mathrm{mm}]}\end{array}$ & $\begin{array}{l}\lambda_{1}=0 \\
\lambda_{2}=0 \\
A_{1}=0 \\
A_{2}=0\end{array}$ & $\begin{array}{l}\lambda_{1}=10 \\
\lambda_{2}=0 \\
A_{1}=0.1250 \\
A_{2}=0\end{array}$ & $\begin{array}{l}\lambda_{1}=10 \\
\lambda_{2}=1 \\
A_{1}=0.1250 \\
A_{2}=0.0500\end{array}$ \\
\hline $\begin{array}{l}\text { Printed } \\
\text { amplitude and } \\
\text { wavelength } \\
\text { [mm] }\end{array}$ & $\begin{array}{l}\lambda_{1}=0 \\
\lambda_{2}=0 \\
A_{1}=0 \\
A_{2}=0\end{array}$ & $\begin{array}{l}\lambda_{1}=10.0030 \\
\lambda_{2}=0 \\
A_{1}=0.1242 \\
A_{2}=0\end{array}$ & $\begin{array}{l}\lambda_{1}=10.0012 \\
\lambda_{2}=1.0063 \\
A_{1}=0.1310 \\
A_{2}=0.0637\end{array}$ \\
\hline $\begin{array}{l}\text { Design } \\
\text { diameter }[\mathrm{mm}]\end{array}$ & 31.6000 & 31.6000 & 31.6000 \\
\hline $\begin{array}{l}\text { Printed } \\
\text { diameter }[\mathrm{mm}]\end{array}$ & 31.5460 & 31.5333 & 31.0547 \\
\hline $\begin{array}{l}\text { Design } \\
\text { clearance [mm] }\end{array}$ & 0.2000 & 0.2000 & 0.2000 \\
\hline $\begin{array}{l}\text { Printed } \\
\text { clearance }[\mathrm{mm}]\end{array}$ & 0.2271 & 0.2334 & 0.4727 \\
\hline
\end{tabular}
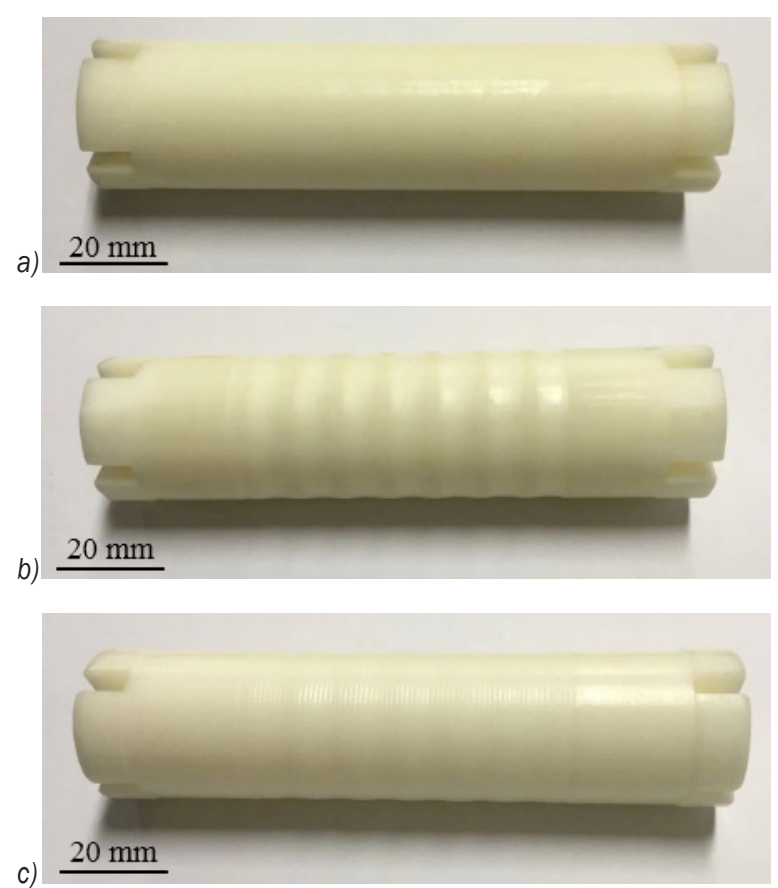

Fig. 3. The specimens: a) the $0^{\text {th }}$ order model, b) the 1st order model and c) the $2^{\text {nd }}$ order model 

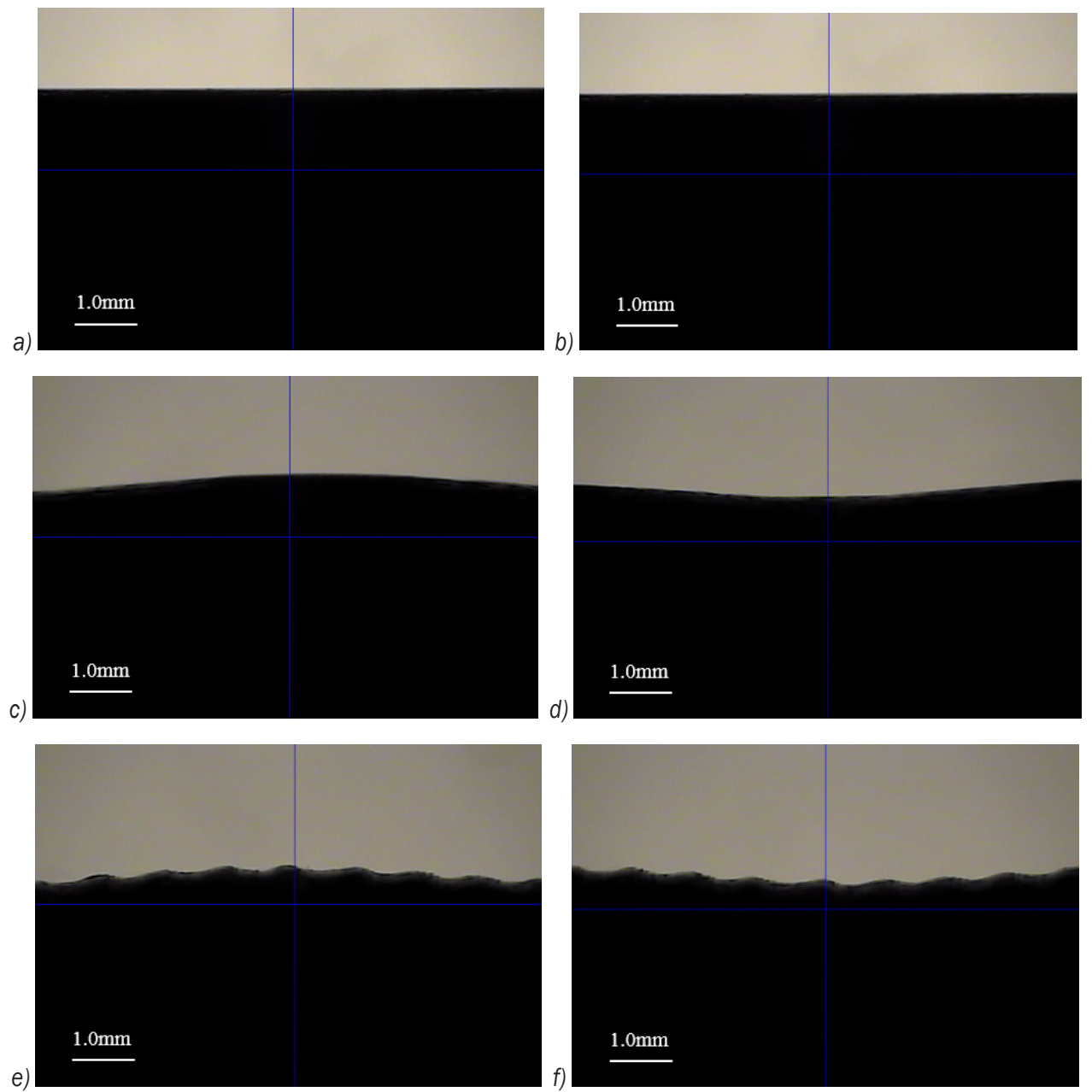

Fig. 4. The enlarged views: a) and b) the $0^{\text {th }}$ order specimen, c) and d) the $1^{\text {st }}$ order specimen, e) and f) the $2^{\text {nd }}$ order specimen

\subsection{Test Procedure and Results}

In our leakage experiments, the internal diameter of the cylinder was $32.0 \mathrm{~mm}$. As shown in Fig. 5, the interference fits between the cylinder and both ends of specimens were used to ensure the same clearance in the circumferential. The water pump was used, and the pressure difference between the inlet and outlet of the test cylinder was set to $0.2 \mathrm{MPa}$ by regulating the throttle valve. The flow through the clearance between the cylinder and specimen was measured by the flow sensor. Clearance leakage flow of the $0^{\text {th }}$, the $1^{\text {st }}$, and $2^{\text {nd }}$ order specimens were tested respectively on the water hydraulic annular clearance test rig. Obtained experimental data are displayed in Table 2 . The results showed that the specimen with $2^{\text {nd }}$ order structures has the largest gap size but the lowest leakage. It is well known that the larger clearance size will result

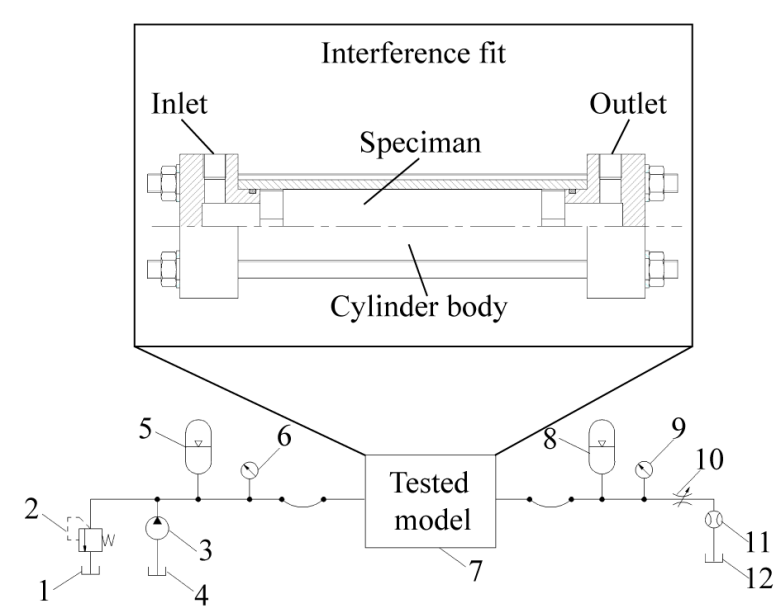

Fig. 5. The schematic of the water hydraulic annular clearance test rig $(1,4,12$ water tank, 2 hydraulic relief valve, 3 water pump, 5, 8 accumulator, 6,9 pressure sensor, 7 rested model, 10 throttle valve, 11 flow sensor) 
in larger leakage flow. Therefore, compared to the $0^{\text {th }}$ order and the $1^{\text {st }}$ order structures, the $2^{\text {nd }}$ order structures can more effectively reduce the clearance leakage. Furthermore, the mechanism underlying the reduced leakage caused by the $2^{\text {nd }}$ order structures was still unclear; thus, the numerical simulation was used to further study the effect of hierarchical sinusoidal morphology on clearance flow.

Table 2. A comparison of numerical simulation results with experimental data

\begin{tabular}{lccc}
\hline Specimen & $0^{\text {th }}$ order & 1st order $^{2^{\text {nd }} \text { order }}$ \\
\hline Leakage by experiment $[\mathrm{kg} / \mathrm{s}]$ & 0.1352 & 0.1647 & 0.1302 \\
\hline Leakage by simulation $[\mathrm{kg} / \mathrm{s}]$ & 0.1426 & 0.1794 & 0.1421 \\
\hline Deviation [\%] & 5.5 & 8.9 & 9.1 \\
\hline
\end{tabular}

\section{NUMERICAL APPROACH}

Reynolds number is the criteria to estimate the flow state, and it is defined as follows:

$$
\operatorname{Re}=\frac{\rho v d_{\mathrm{H}}}{\mu},
$$

where $\rho$ is the density, $v$ is the velocity, $\mu$ is the viscosity, and $d_{\mathrm{H}}$ is the hydraulic diameter. For the annular gap, $d_{\mathrm{H}}=2 h, h$ is the unilateral clearance size. Critical flow $q_{\mathrm{c}}$ can be written as:

$$
\begin{aligned}
q_{\mathrm{c}} & =A v_{\mathrm{c}}=\frac{\operatorname{Re}_{\mathrm{c}} \mu}{\rho d_{\mathrm{H}}} \cdot \pi\left(r_{1}+r_{2}\right) h \\
& =\frac{\operatorname{Re}_{\mathrm{c}} \mu \pi\left(r_{1}+r_{2}\right)}{2 \rho},
\end{aligned}
$$

where $\operatorname{Re}_{\mathrm{c}}$ is the critical Reynolds number, $r_{1}$ is the inner radius of the cylinder, and $r_{2}$ is the radius of the specimen. While the flow is larger than $q_{\mathrm{c}}$, the fluid flow transfer is from laminar to turbulent. For the tested models, the mass flow is larger than $q_{\mathrm{c}}$; then it can be deduced that turbulent flow is generated in the clearance between the specimen and the cylinder.

Leakage flow is defined by the pressure difference over the seal. The clearance sealing performance of water hydraulic components under various pressure difference have been studied: $0.02 \mathrm{MPa}$ [32], $0.2 \mathrm{MPa}$ [33] and [34], 0.4 $\mathrm{MPa}$ [33], 0.41 $\mathrm{MPa}$ [35], 0.6 $\mathrm{MPa}$ [33], 1.5 MPa [36], $2 \mathrm{MPa}$ [36] and [37], 2.5 $\mathrm{MPa}$ [36], $5 \mathrm{MPa}$ [38], $10 \mathrm{MPa}$ [38], $15 \mathrm{MPa}$ [38], $20 \mathrm{MPa}$ [38].In this article, the pressure difference between the inlet and outlet was set as $0.2 \mathrm{MPa}$. A two-dimensional (2D) axisymmetric model was adopted, and water was chosen as the working fluid. The clearances of the $0^{\text {th }}$ order, the $1^{\text {st }}$ order, and the $2^{\text {nd }}$ order models were set as $0.2271 \mathrm{~mm}, 0.2334 \mathrm{~mm}$, and $0.4727 \mathrm{~mm}$, respectively, which were consistent with the clearance sizes used in experiments. To replicate conditions of the experimental setup, matching surfaces were treated as wall boundaries for numerical simulations. This study has been carried out with the commercial computational fluid dynamics (CFD) package from ANSYS FLUENT. A re-normalisation group (RNG) $k-\varepsilon$ model was used to predict the clearance turbulent flow. This model is a two-equation turbulence model that is derived by using renormalization group methods [39]; it significantly improves the responsiveness to the effects of rapid strain and streamline curvature [40] and [41] and predicts more swirls and has better treatment of near-wall turbulence effects [42] and [43]. It predicted well the numerical results that agree with experimental results. The SIMPLEC algorithm is implemented in FLUENT, and the pressurebased solver and Green-Gauss node-based gradient treatment were chosen to obtain fast and accurate converging solutions for unstructured triangular grids. $2^{\text {nd }}$ order discretization scheme was used for all governing equations. The desired convergence target was that the root mean square residuals of the momentum and mass equations, energy equation, and turbulence equations would reach $10^{-5}$.

The whole mesh generation process was carried out in Pointwise 17.4 software. The computational model was qualified with unstructured triangular mesh, and the schematic diagrams of the grid are shown in Fig. 6. Refined meshes are adapted at both the inlet/outlet and wall boundaries to capture the detailed flowing behaviour, while relatively coarser mesh was used in other regions. Furthermore, grid dependence and convergence studies were performed, as depicted in Fig. 7. The selected nodes number of computational models in this paper is around 150,000 to 200,000 . With this resolution, obtaining a stationary solution required approximately 200 minutes on an Intel E5 workstation with 32G/2133ECC. Finally, the mass flow of the $0^{\text {th }}$ order, the $1^{\text {st }}$ order and the $2^{\text {nd }}$ order models were calculated numerically. The results are shown in Table 2; it can be seen from the numerical simulation results that the $2^{\text {nd }}$ order one has the least leakage flow, and the $1^{\text {st }}$ order one is with the largest flow. Furthermore, numerical simulation has shown a good agreement with experimental data, with errors of less than $10 \%$. The simulation methods were verified with our experiments. 

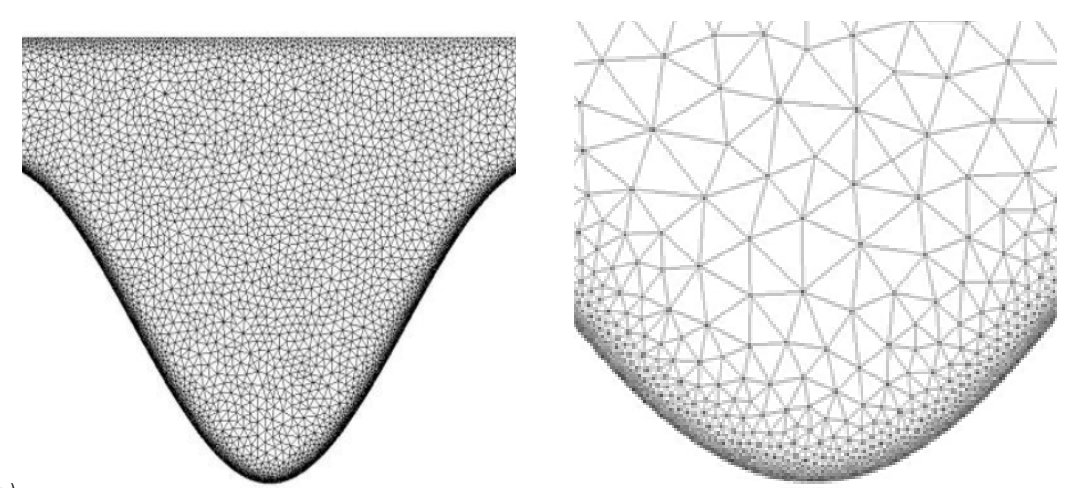

a)
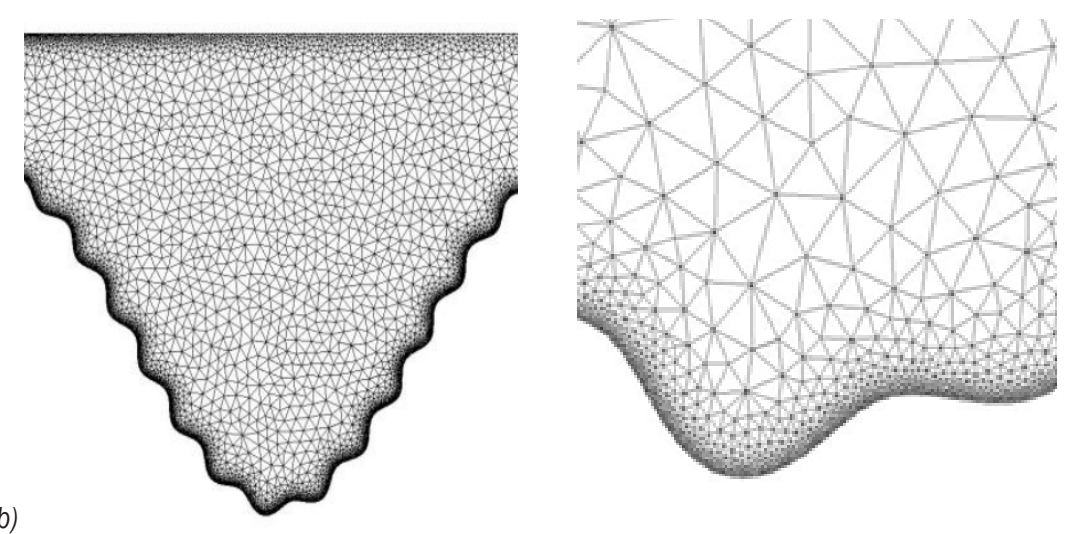

Fig. 6. Meshes used for models: a) The $1^{\text {st }}$ order model; $b$ ) the $2^{\text {nd }}$ order model

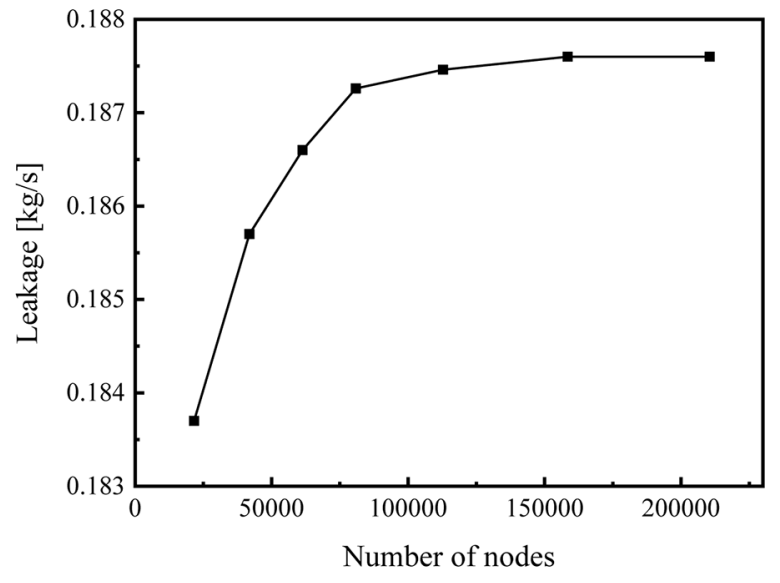

Fig. 7. An example of grid dependence of the CFD results

\section{THE EFFECT OF VARIOUS SINUSOIDAL MORPHOLOGY ON LEAKAGE}

\subsection{Simulation Models}

The numerical investigation for the effect of multilevel sinusoidal morphology on leakage was carried out with various amplitudes and wavelengths. Matching surfaces were assumed to be rigid bodies, and the temperature of the fluid was assumed to be constant in this paper, in order to focus on the influences of the surface morphology on clearance flow. The $1^{\text {st }}$ order models were controlled by the amplitude $A_{1}$ of $0.25 \mathrm{~mm}, 0.5 \mathrm{~mm}$ and $1.0 \mathrm{~mm}$, and the wavelength $\lambda_{1}$ within the range of $0.125 \mathrm{~mm}$ to $10 \mathrm{~mm}$. The parameters of the $2^{\text {nd }}$ order model, $A_{2}$ equals to 0.01 $\mathrm{mm}, 0.03 \mathrm{~mm}$ and $0.05 \mathrm{~mm}$, respectively, and $\lambda_{2}$ takes value in $0.02 \mathrm{~mm}$ to $0.4 \mathrm{~mm}$. As shown in Fig. 2, three kinds of 2D axisymmetric models were calculated. The length, $l$, was set to be $10 \mathrm{~mm}$, the clearance, $\delta$, equals to $0.2 \mathrm{~mm}$.

\subsection{Influence of the 1st Order Sinusoidal Morphology on Sealing Performance}

A dimensionless parameter, $Q_{1} / Q_{0}$, was introduced to estimate the seal efficiency of the $1^{\text {st }}$ order model compared to the $0^{\text {th }}$ order one, and another dimensionless parameter, $\varepsilon_{1}$, was defined by $A_{1} / \lambda_{1}$, to characterize the surface shape of the $1^{\text {st }}$ order sinusoidal morphology. Firstly, the $0^{\text {th }}$ order 
model was simulated numerically, giving numerical leakage flow of $Q_{0}=0.5545 \mathrm{~kg} / \mathrm{s}$. Similarly, leakage $Q_{1}$ for the waved surface of varying amplitudes and wavelengths, for $1^{\text {st }}$ order models were obtained and compared with the $0^{\text {th }}$ order model under the same operating conditions. As shown in Fig. 8, the water leakage $Q_{1} / Q_{0}$ decreases firstly and then increases with the increments in parameter $\varepsilon_{1}$. The lowest leakage $Q_{1}$ was achieved at $A_{1}=1 \mathrm{~mm}, \varepsilon_{1}=4$ with up to $43.3 \%$ reduction in $\left(1-Q_{1} / Q_{0}\right)$. However, as the small value of parameter $\varepsilon_{1}$ is taken, the sealing performance is worsened by the $1^{\text {st }}$ order sinusoidal structure. Specifically, as the value of $\varepsilon_{1}$ is less than $0.15,0.2$ and 0.4 for the three models respectively $\left(A_{1}=0.25 \mathrm{~mm}, 0.5 \mathrm{~mm}\right.$ and $\left.1.0 \mathrm{~mm}\right)$, the value of $Q_{1} / Q_{0}$ is more than 1 .

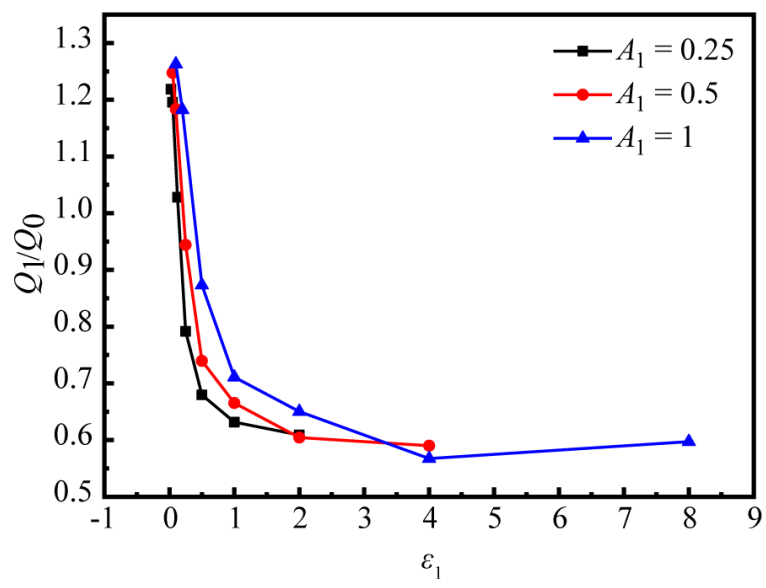

Fig. 8. The seal efficiency of the 1 st order models

\subsection{Influence of the $2^{\text {nd }}$ Order Sinusoidal Morphology on Sealing Performance}

The $2^{\text {nd }}$ order models with sinusoidal morphology superimposed on the 1 st order model of $A_{1}=0.25$ $\mathrm{mm}$ and $\lambda_{1}=1 \mathrm{~mm}$ were established and computed. The dimensionless parameter $\varepsilon_{2}$ was defined by $A_{2} / \lambda_{2}$, to characterize the waved shape of the $2^{\text {nd }}$ order sinusoidal morphology. Fig. 9 depicts the sealing efficiency of the $2^{\text {nd }}$ order sinusoidal morphology models. The leakages of the $2^{\text {nd }}$ order models are lower than that of the $1^{\text {st }}$ order models. In detail, it can be seen that the maximum leakage reduction $\left(1-Q_{2} / Q_{1}\right)$ is $18 \%$, which means the sealing efficiency is effectively improved by the $2^{\text {nd }}$ order sinusoidal morphology. However, when the parameter $\varepsilon_{2}$ is relatively small, larger leakage is generated due to the existence of larger clearance fields and less energy dissipation.

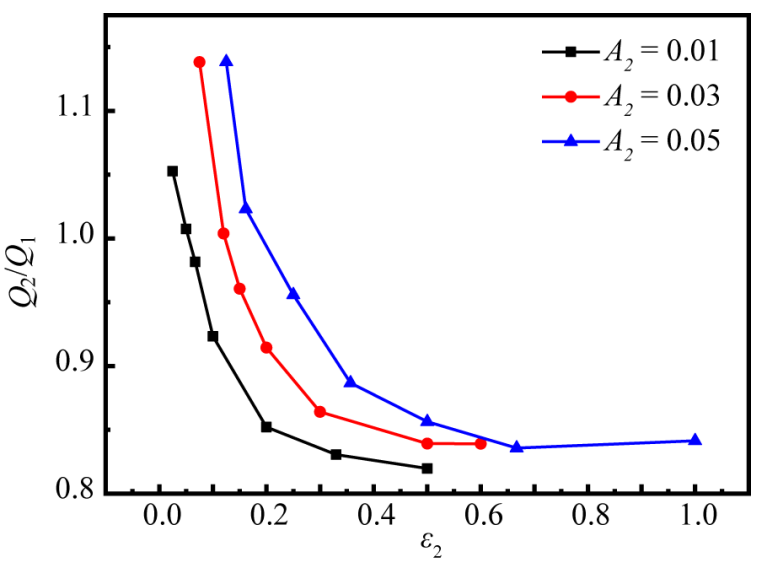

Fig. 9. The seal efficiency of the $2^{\text {nd }}$ order models

\section{FLUID FIELD ANALYSIS}

To further explore the sealing performance of the $1^{\text {st }}$ order and the $2^{\text {nd }}$ order models, their streamlines distributions were plotted in Figs. 10a and b, respectively. The enlarged local views of the $2^{\text {nd }}$ order wavy teeth were also presented in Fig. 10c for better observation. As indicated in Fig. 10a, one big rotating vortex is observed in each cell of the 1 ${ }^{\text {st }}$ order model, which causes a decrease in leakage by dissipating fluid kinetic energy. Similarly, for the $2^{\text {nd }}$ order model, a big vortex is also generated in the middle region of each cavity, as shown in Fig. 10b. More interestingly, numerous $3^{\text {rd }}$ order vortexes with reverse rotation can be found in the $2^{\text {nd }}$ order wavy cavities. Moreover, the tertiary vortexes can also be found at the teeth tips of the throttling area of the $2^{\text {nd }}$ order model, as shown in Fig. 10c. All the vortexes in various levels will contribute to dissipate more fluid kinetic energy resulting in a reduction in leakage in the case of the $2^{\text {nd }}$ order model. In addition, compared to the $1^{\text {st }}$ order model, a narrower-width main flow was generated by introducing the hierarchical sinusoidal morphology in the $2^{\text {nd }}$ order model, which would lead to less leakage in the $2^{\text {nd }}$ order model.

The velocity of the main flow along the $X$ direction plays a major role in surface wear and gap leakage. The $X$ component of velocity contour was shown in Fig. 11. The results show that the velocity of flow in clearance is $6 \mathrm{~m} / \mathrm{s}$ to $13 \mathrm{~m} / \mathrm{s}$ in the 1 st order model, but $4 \mathrm{~m} / \mathrm{s}$ to $11 \mathrm{~m} / \mathrm{s}$ in the $2^{\text {nd }}$ order model. Lower velocity along the $X$ direction in the $2^{\text {nd }}$ order model helps achieve less fluid erosion between the matching surfaces, and it also gives a further explanation for its lower leakage. The high-velocity fluid through the clearances will cause the fluid 

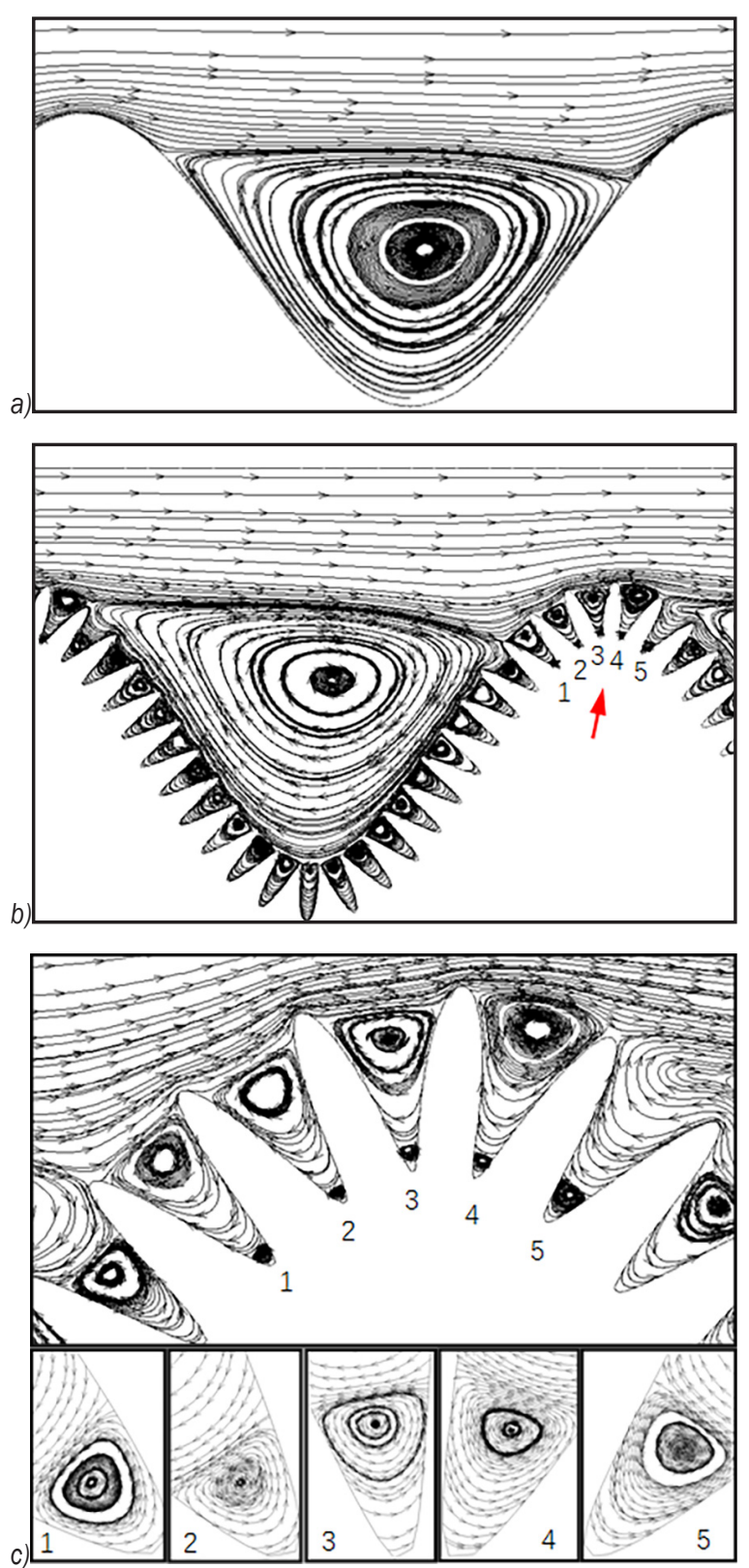

Fig. 10. Streamlines distributions: a) the 1st order model; b) the $2^{\text {nd }}$ order model; c) the enlarged views of the $2^{\text {nd }}$ order models (arrows in b)

erosion, called "wire drawing". Moreover, the wear of the matching surfaces will also inevitably enlarge the clearance, which will increase the leakage. Fig. 12 depicts the statistical results of velocity magnitudes in the flow field of the $1^{\text {st }}$ order and $2^{\text {nd }}$ order models. The velocity magnitude in about $70 \%$ fluid fields is less than $3 \mathrm{~m} / \mathrm{s}$ for the $1{ }^{\text {st }}$ order model. Comparatively, about $85 \%$ zones of the $2^{\text {nd }}$ order model are with the velocity of less than $1 \mathrm{~m} / \mathrm{s}$.
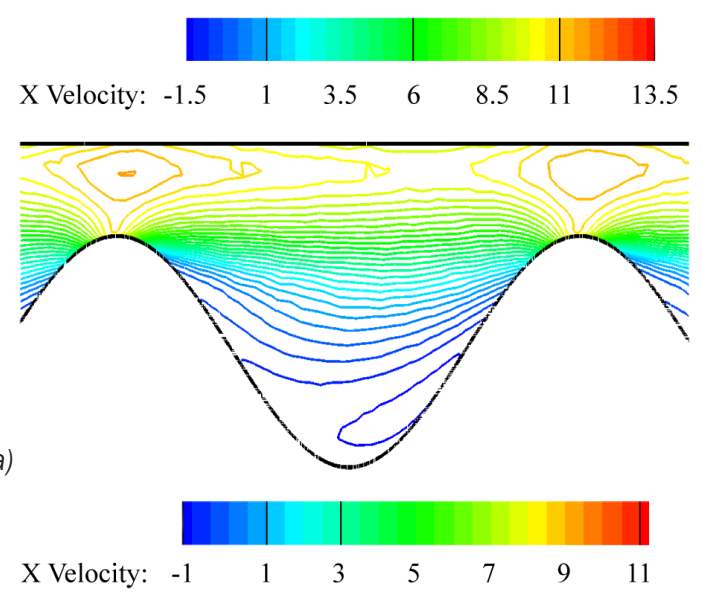

b)

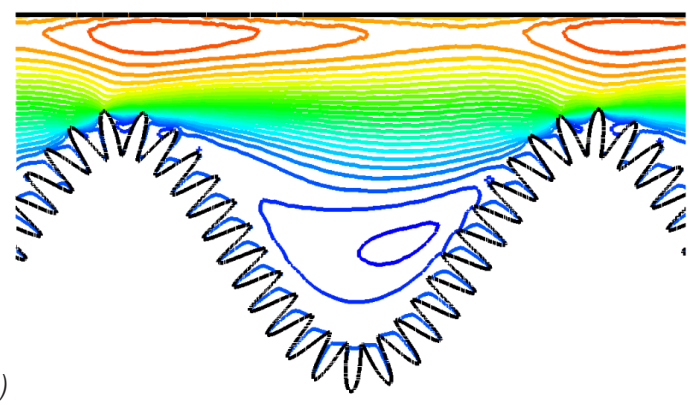

Fig. 11. The $X$ velocity component contours: a) the $1^{\text {st }}$ order model; $b$ ) the $2^{\text {nd }}$ order model
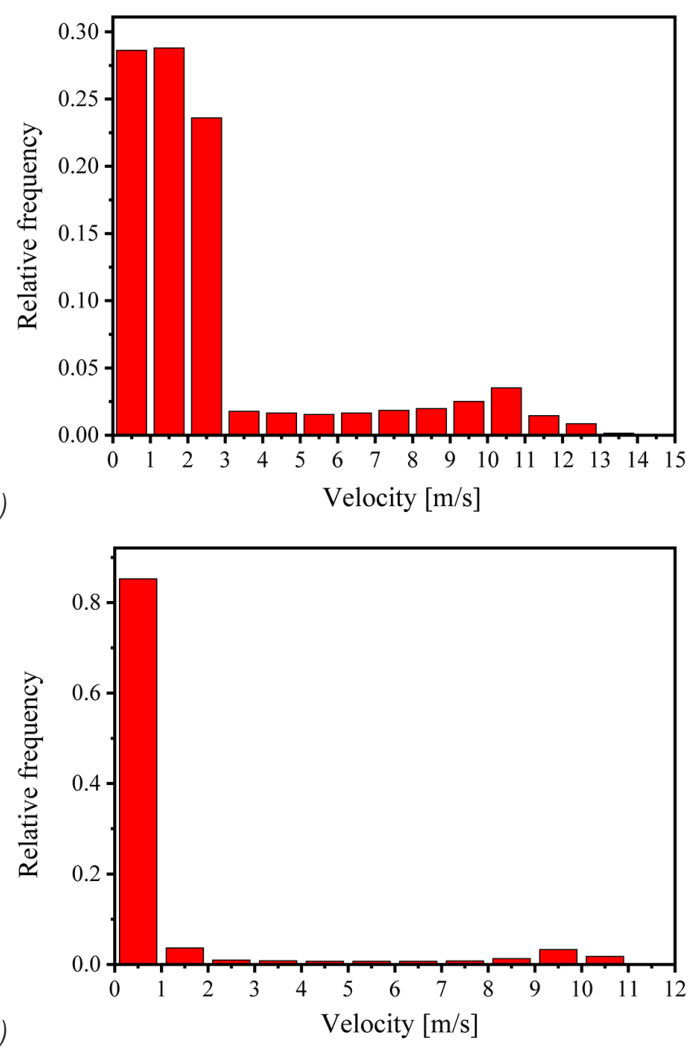

Fig. 12. The statistics of velocity magnitudes in flow fields: a) the $1^{\text {st }}$ order model; $b$ ) the $2^{\text {nd }}$ order model 
Surfacing texturing is a powerful method of enhancing hydrodynamic load carrying capacity. As indicated in Fig. 13, the pressure distribution of models with the $0^{\text {th }}$ order, $1^{\text {st }}$ order and $2^{\text {nd }}$ order structures were given respectively. Firstly, the pressure decreases smoothly from the inlet to the outlet for the $0^{\text {th }}$ order model but drops gradually for the $1^{\text {st }}$ order and $2^{\text {nd }}$ order models, and the pressure in the $2^{\text {nd }}$ order gap drops faster than that of the other two models. Moreover, the waved surface generated numbers of
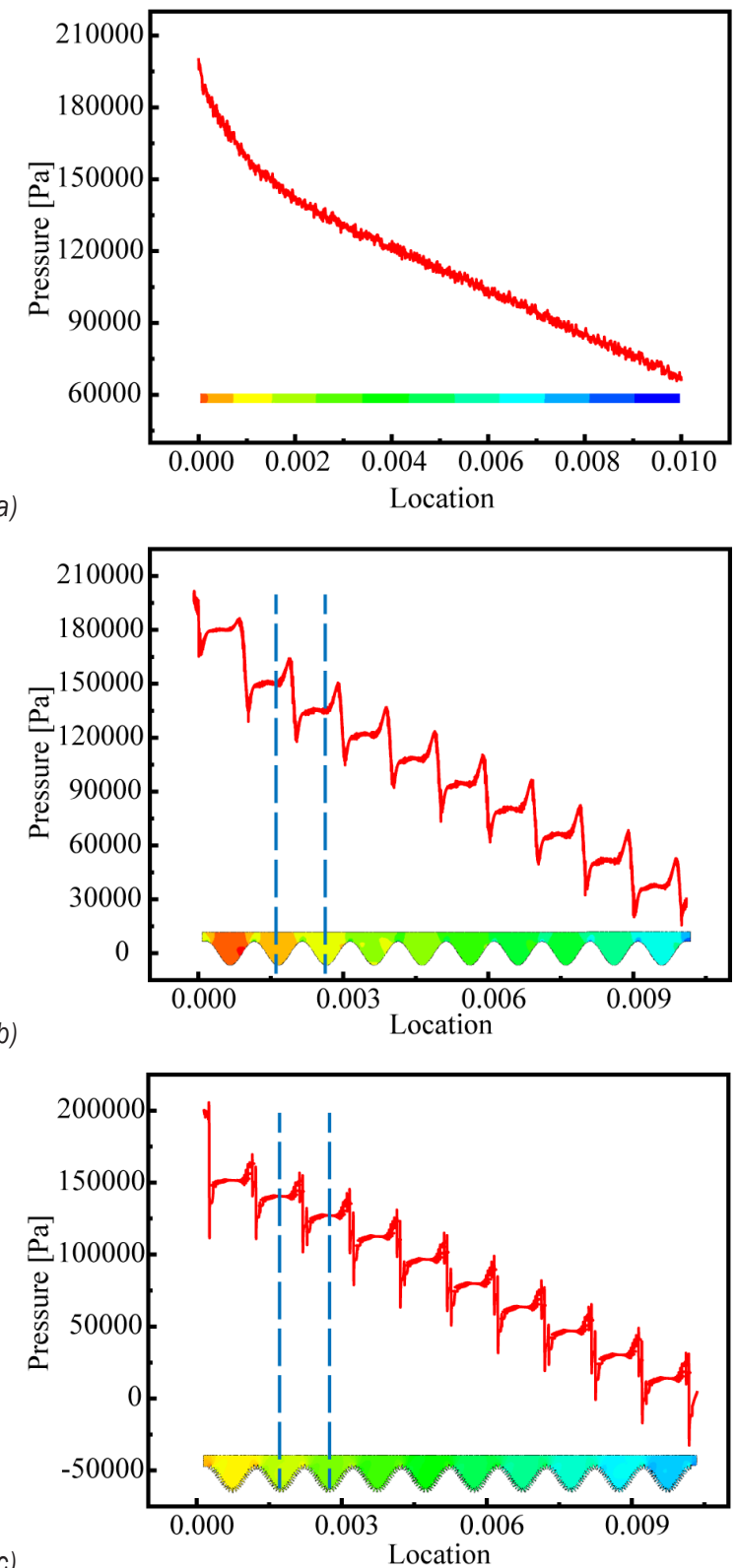

Fig. 13. Comparisons of pressure distribution: a) the $0^{\text {th }}$ order model; b) the 1 st order model; c) the $2^{\text {nd }}$ order model convergent wedge-shaped areas in the clearance, causing changes in the thickness of the fluid film, which contribute to additional hydrodynamic pressure generation. As shown in Figs. 13b and c, the pressure mainly dropped at peaks but remained stable in the chambers of waved troughs. Furthermore, for each peak in the waved surface, there is a corresponding peak in the pressure field. A micro-hydrodynamic effect was induced by the waved surface and created an additional load carrying capability, separating the matching surfaces.

\section{CONCLUSIONS}

The hierarchical sinusoidal morphology was introduced to the clearance of matching surfaces in water hydraulic systems where poorer lubricity and larger leakage exist due to the lower viscosity of water. Both the numerical and experimental results show that introducing hierarchical morphology on matching surfaces will reduce leakage. The models of the $0^{\text {th }}$ order, the $1^{\text {st }}$ order and the $2^{\text {nd }}$ order with various amplitudes and wavelengths were studied. For the $1^{\text {st }}$ order and the $2^{\text {nd }}$ order models, the leakage reduces with the increase in the ratio of the amplitude to wavelength. Further study of the flow field reveals that the significant leakage reductions of the $2^{\text {nd }}$ order sinusoidal models are obtained due to the extra vortexes of various scales in the $2^{\text {nd }}$ order wavy cavities, which dissipate more fluid kinetic energy, contributing towards a mechanism to reduce leakage. In addition, the narrower width of the main flow and lower $X$ component of velocity in the $2^{\text {nd }}$ order models compared to that of the $1^{\text {st }}$ order models also make contributions to the lower leakage. Moreover, the waved surfaces produce changes in the thickness of the fluid film, which contributes to create an additional load carrying capability and reduce wear. We conclude that the exciting results obtained from introducing the hierarchical waved surface have a huge potential application to reduce energy loss in hydraulic systems and give a new way to design clearances between matching surfaces.

\section{ACKNOWLEDGEMENTS}

Supports from the National Natural Science Foundation of China (Grant No. 51475197) are acknowledged. 


\section{NOMENCLATURE}

$A_{1} \quad$ amplitude of 1 st order cosinoidal waviness, [mm]

$A_{2}$ amplitude of $2^{\text {nd }}$ order cosinoidal waviness, [mm]

$\lambda_{1}$ wavelength of $1^{\text {st }}$ order consinoidal waviness, [mm]

$\lambda_{2}$ wavelength of $2^{\text {nd }}$ order consinoidal waviness, [mm]

$\varepsilon_{1} \quad$ dimensionless parameter, defined by $A_{1} / \lambda_{1}$

$\varepsilon_{2}$ dimensionless parameter, defined by $A_{2} / \lambda_{2}$

$Q_{0}$ leakage of straight labyrinth seal, $[\mathrm{kg} / \mathrm{s}]$

$Q_{1}$ leakage of 1st order labyrinth seal, $[\mathrm{kg} / \mathrm{s}]$

$Q_{2}$ leakage of 2nd order labyrinth seal, [kg/s]

$L \quad$ length of labyrinth seals, [mm]

$\delta \quad$ clearance of labyrinth seals, $[\mathrm{mm}]$

$\rho$ density, $\left[\mathrm{kg} / \mathrm{m}^{3}\right]$

$\mu$ Viscosity, $[\mathrm{Pa} \cdot \mathrm{s}]$

$d_{\mathrm{H}}$ hydraulic diameter, [mm]

$v$ Velocity, $[\mathrm{m} / \mathrm{s}]$

$h$ unilateral clearance size, $[\mathrm{mm}]$

$q_{\mathrm{c}}$ critical flow, $[\mathrm{kg} / \mathrm{s}]$

\section{REFERENCES}

[1] Lim, G.H., Chua, P.S.K., He, Y.B. (2003). Modern water hydraulics-the new energy-transmission technology in fluid power. Applied Energy, vol. 76, no. 1-3, p. 239-246, DOI:10.1016/s0306-2619(03)00064-3.

[2] Urata, E. (1999). Technological aspects of the new water hydraulics. Proceedings of The $6^{\text {th }}$ Scandinavian International Conference on Fluid Power, p. 21-34.

[3] Krutz, G.W., Chua, P.S. (2004). Water hydraulics-theory and applications. Workshop on Water Hydraulics, Agricultural Equipment Technology Conference, p. 8-10.

[4] Koskinen, K.T., Leino, T., Riipinen, H. (2008). Sustainable development with water hydraulics-possibilities and challenges. Proceedings of the JFPS International Symposium on Fluid Power, no. 7-1, p. 11-18, D0l:10.5739/isfp.2008.11.

[5] Etsion, I. (2004). State of the art in laser surface texturing. ASME $7^{\text {th }}$ Biennial Conference on Engineering Systems Design and Analysis, p. 585-593, D0I:10.1115/ESDA2004-58058.

[6] Pantelis, D.I., Pantazopoulos, G., Antoniou, S.S. (1997). Wear behavior of anti-galling surface textured gray cast iron using pulsed- $\mathrm{CO}_{2}$ laser treatment. Wear, vol. 205, no. 1-2, p. 178185, D0I:10.1016/s0043-1648(96)07339-5.

[7] Dumitru, G., Romano, V., Weber, H.P, Haefke, H., Gerbig, Y., Pflüger, E. (2000). Laser microstructuring of steel surfaces for tribological applications. Applied Physics A, vol. 70, no. 4, p. 485-487, DOl:10.1007/s003390051073.

[8] Bifeng, Y., Dashu, G., Shao, S., Bo, X., Hekun, J. (2018). Research on the profile design of surface texture in piston ring of internal combustion engine. Journal of Tribology, vol. 140, no. 6, p. 061701, D0l:10.1115/1.4039957.

[9] Wang, X., Kato, K., Adachi, K., Aizawa, K. (2001). The effect of laser texturing of SiC surface on the critical load for the transition of water lubrication mode from hydrodynamic to mixed. Tribology International, vol. 34, no. 10, p. 703-711, DOl:10.1016/S0301-679X(01)00063-9.

[10] Shen, C., Khonsari, M. (2016). Tribological and sealing performance of laser pocketed piston rings in a diesel engine. Tribology Letters, vol. 64, no. 2, p. 26, D0l:10.1007/s11249016-0757-9.

[11] Erinosho, M.F., Akinlabi, E.T. (2018). Influence of laser power on improving the wear properties of laser-deposited Ti-6Al4V+B4C composite. Strojniski vestnik - Journal of Mechanical Engineering, vol. 64, no. 7-8, p. 488-495, Dol:10.5545/svjme.2018.5362.

[12] Usman, A., Park, C.W. (2017). Numerical investigation of tribological performance in mixed lubrication of textured piston ring-liner conjunction with a non-circular cylinder bore. Tribology International, vol. 105, p. 148-157, D0l:10.1016/j. triboint.2016.09.043.

[13] Nanbu, T., Ren, N., Yasuda, Y., Zhu, D., Wang, Q.J. (2008). Micro-textures in concentrated conformal-contact lubrication: Effects of texture bottom shape and surface relative motion. Tribology Letters, vol. 29, no. 3, p. 241-252, D0l:10.1007/ s11249-008-9302-9.

[14] Shen, C. (2016). Design of Surface Texture for the Enhancement of Tribological Performance. PhD thesis Louisiana State University and Aqricultural and Mechanical College, Baton Rouge.

[15] Zabala, B., Igartua, A., Férnandez, X., Priestner, C., Ofner, H., Knaus, O., Abramczuk, M., Tribotte, P., Girot, F., Roman, E., Nevshupa, R. (2017). Friction and wear of a piston ring/ cylinder liner at the top dead centre: Experimental study and modelling. Tribology International, vol. 106, p. 23-33, D0I:10.1016/j.triboint.2016.10.005.

[16] Rao, X., Sheng, C., Guo, Z., Yuan, C. (2019). Influence of surface groove width on tribological performance for cylinder liner-piston ring components. Tribology Transactions, in Press, p. 1-10, DOl:10.1080/10402004.2018.1539201.

[17] Etsion, I., Halperin, G. (2002). A laser surface textured hydrostatic mechanical seal. Tribology Transactions, vol. 45, no. 3, p. 430-434, DOl:10.1080/10402000208982570.

[18] Etsion, I. (2013). Modeling of surface texturing in hydrodynamic lubrication. Friction, vol. 1, no. 3, p. 195-209, DOI:10.1007/s40544-013-0018-y.

[19] Han, Y., Fu, Y. (2018). Investigation of surface texture influence on hydrodynamic performance of parallel slider bearing under transient condition. Meccanica, vol. 53, no. 8, p. 2053-2066, D0I:10.1007/s11012-017-0809-8.

[20] Kango, S., Sharma, R.K., Pandey, R.K. (2014). Comparative analysis of textured and grooved hydrodynamic journal bearing. Proceedings of the Institution of Mechanical Engineers, Part J: Journal of Engineering Tribology, vol. 228, no. 1, p. 82-95, Dol:10.1177/1350650113499742.

[21] Bergseth, E., Sjöberg, S.r., Björklund, S. (2012). Influence of real surface topography on the contact area ratio in differently manufactured spur gears. Tribology International, vol. 56, p. 72-80, D0I:10.1016/j.triboint.2012.06.014.

[22] Bergseth, E., Olofsson, U., Lewis, R., Lewis, S. (2012). Effect of gear surface and lubricant interaction on mild wear. Tribology Letters, vol. 48, no. 2, p. 183-200, D0l:10.1007/s11249-0120004-y. 
[23] Wondergem, A.M., Ivantysynova, M. (2014). The impact of the surface shape of the piston on power losses. In $8^{\text {th }} \mathrm{FPNI}$ Ph. D Symposium on Fluid Power, p. V001T02A008, DOl:10.1115/fpni2014-7843.

[24] Ivantysynova, M. (2012). The piston cylinder assembly in piston machines-a long journey of discovery. Proceedings of $8^{\text {th }}$ IFK International Conference on Fluid Power, p. 307-332.

[25] Ivantysynova, M., Lasaar, R. (2004). An investigation into micro-and macrogeometric design of piston/cylinder assembly of swash plate machines. International Journal of Fluid Power, vol. 5, no. 1, p. 23-36, Dol:10.1080/14399776.2004.107811 81.

[26] Kleist, A. (1997). Design of hydrostatic bearing and sealing gaps in hydraulic machines: a new simulation tool. 5th Scandinavian International Conference on Fluid Power, p. 157-169.

[27] Ivantysynova, M., Baker, J. (2009). Power loss in the lubricating gap between cylinder block and valve plate of swash plate type axial piston machines. International Journal of fluid power, vol. 10, no. 2, p. 29-43, DOl:10.1080/14399776.2009.10780976.

[28] Pelosi, M., Ivantysynova, M. (2011). Surface deformations enable high pressure operation of axial piston pumps. ASME Dynamic Systems and Control Conference and ASME Symposium on Fluid Power and Motion Control, p. 193-200, DOI:10.1115/dscc2011-5979.

[29] Shin, J.-H., Kim, K.-W. (2014). Effect of surface non-flatness on the lubrication characteristics in the valve part of a swashplate type axial piston pump. Meccanica, vol. 49, no. 5, p. 1275-1295, DOI:10.1007/s11012-014-9893-1.

[30] Wang, J.-S., Wang, G., Feng, X.-Q., Kitamura, T., Kang, Y.-L., Yu, S.-W., Qin, Q.-H. (2013). Hierarchical chirality transfer in the growth of towel gourd tendrils. Scientific Reports, vol. 3, p. 3102, D0I:10.1038/srep03102.

[31] Li, B.-W., Zhao, H.-P., Qin, Q.-H., Feng, X.-Q., Yu, S.-W. (2012). Numerical study on the effects of hierarchical wavy interface morphology on fracture toughness. Computational Materials Science, vol. 57, p. 14-22, D0l:10.1016/j. commatsci.2011.01.032.

[32] Saba Y., Basim A., Nehad A.(2014). Prediction of carry-over coefficient for fluid flow through teeth on rotor labyrinth seals using computational fluid dynamics. Iraqi Journal of Mechanical and Material Engineering, vol. 14, no. 3, p. 346366.

[33] Ma, R., Wang, K. (2010). CFD numerical simulation and experimental study of effects of screw-sleeve fitting clearance upon triangular thread labyrinth screw pump (LSP) performance. Journal of Applied Fluid Mechanics, vol. 3, no. 1, p. $75-81$.

[34] Watson, C., Untaroiu, A., Wood, H.G., Weaver, B.K., Morgan, N., Jin, H. (2016). Response surface mapping of performance for helical groove seals with incompressible flow. ASME Turbo Expo: Turbomachinery Technical Conference and Exposition, p. V07BT31A036, D0I:10.1115/gt2016-57945.

[35] Demko, J.A., Morrison, G.L., Rhode, D.L. (1989). The prediction and measurement of incompressible flow in a labyrinth seal. Journal of Engineering for Gas Turbines and Power, vol. 111, no. 4, p. 697-702, D0I:10.1115/1.3240315.

[36] Marsis, E., Morrison, G. (2013). Leakage and rotordynamics numerical study of circular grooved and rectangular grooved labyrinth seals. ASME Turbo Expo: Turbine Technical Conference and Exposition, p. V07AT29A028, D0l:10.1115/ GT2013-96001.

[37] Zhao, W., Nielsen, T.K., Billdal, J.T. (2010). Effects of cavity on leakage loss in straight-through labyrinth seals. IOP Conference Series: Earth and Environmental Science, vol. 12, p. 012002, D0I:10.1088/1755-1315/12/1/012002.

[38] Strmčnik, E., Majdič, F. (2017). Comparison of leakage level in water and oil hydraulics. Advances in Mechanical Engineering, vol. 9, no. 11, p. 1-12, Dol:10.1177/1687814017737723.

[39] Smith, L.M., Woodruff, S.L. (1998). Renormalization-group analysis of turbulence. Annual Review of Fluid Mechanics, vol. 30, no. 1, p. 275-310, Dol:10.1146/annurev.fluid.30.1.275.

[40] Govardhan, M., Sampat, D.L. (2005). Computational studies of flow through cross flow fans-effect of blade geometry. Journal of Thermal Science, vol. 14, no. 3, p. 220-229, D0l:10.1007/ s11630-005-0005-3.

[41] Myong, H.K., Yang, S.Y. (2003). Numerical study on flow characteristics at blade passage and tip clearance in a linear cascade of high performance turbine blade. KSME International Journal, vol. 17, no. 4, p. 606-616, D0l:10.1007/ bf02984462.

[42] Nayak, K., Ansari, A., Musthafa, M., De, S. (2013). The effect of rub-grooves on leakage and windage heating in labyrinth seals with honeycomb lands. 43 ${ }^{\text {rd }}$ AIAA/ASME/ SAE/ASEE Joint Propulsion Conference \& Exhibit, p. 5737, DOI:10.2514/6.2007-5737.

[43] Pospelov, A.Y., Zharkovskii, A.A. (2015). Effect of the parameters of a computational model on the prediction of hydraulic turbine characteristics. Power Technology and Engineering, vol. 49, no. 3, p. 159-164, Dol:10.1007/s10749015-0591-5. 